\title{
The New News about Lithium: An Underutilized Treatment in the United States
}

\author{
Robert M Post*, I \\ 'George Washington University School of Medicine, Bipolar Collaborative Network, Bethesda, MD, USA
}

Lithium use for the treatment of mood disorders remains quite low, particularly in the United States compared with some European countries. Mogens Schou pioneered the study of lithium for prophylaxis of the recurrent mood disorder and encouraged its greater use. In an effort to further address the appropriate role of this drug, the multiple assets of lithium beyond its well-known antimanic effect are reviewed, and a brief summary of its side effects is outlined. It appears that lithium has positive effects in depression and suicide prevention, cognition, and reducing the incidence of dementia. It increases the length of telomeres and has positive effects in prevention of some medical illnesses. Lithium side-effect burden, especially its association with end-stage renal disease, may be less than many have surmised. New data indicate the importance of long-term prophylaxis after a first manic episode to lessen episode recurrence, allow cognition to recover to normal, and prevent various aspects of illness progression. After a first manic episode, I year of randomized treatment with lithium was superior to that of quetiapine, suggesting the importance of having lithium in the treatment regimen. Given the highly recurrent and progressive course of bipolar disorder sometimes even in the face of conventional treatment, the role and enhanced use of lithium deserves reconsideration.

Neuropsychopharmacology (2018) 43, II74-1 179; do::I0.1038/npp.2017.238; published online 8 November 2017

\section{INTRODUCTION}

Mogens Schou was passionate about the use of lithium and compassionate about patients using lithium to better their lives. It was a great honor for this author to receive an award from the International Society for Bipolar Disorders (ISBD) in Schou's name, and I would like to take up his call for the greater use of lithium as a way of improving peoples' lives. Schou himself said that 'for me every single patient whose life was changed radically, out weighs any honors or awards.' (Grof, 2006).

So why does one of the oldest drugs in our pharmacopeia need a new pitch? Like Schou and many others, I believe lithium is underutilized, particularly in the United States. Many residents and young practitioners are not taught about the details of its use and may not be knowledgeable about some of its properties. Schou, who died in 2005, would have wanted this commentary to update lithium's range of positive effects and to reinfuse enthusiasm about its greater use.

Here, I summarize some of the assets of lithium beyond its well-known antimanic properties. Some of these are well documented, and several are new, preliminary, but

* Correspondence: Dr RM Post, George Washington University School of Medicine, Bipolar Collaborative Network, 5415 W Cedar Lane, Suite 20 I-B, Bethesda, MD 208|4, USA, Tel: + | 30 | 530 8245, Fax: + | 30 | 530 8247, E-mail: robert.post@speakeasy.net

Received 26 June 2017; revised 7 September 2017; accepted 14 September 2017; accepted article preview online 4 October 2017 nonetheless highly intriguing and of great potential clinical value. The current status of lithium-related side effects is briefly summarized, as there appear to be many misperceptions about its tolerability and toxicity. An attempt is made to integrate the potential role of lithium into the evolving recommendations for earlier and more effective pharmacoprophylaxis of bipolar disorder.

\section{MATERIALS AND METHODS}

The recent literature is reviewed to selectively highlight various aspects of lithium's wide spectrum of clinical effectiveness. Side effects are briefly noted. This brief summary of lithium's assets, side effects, and mechanisms of action is not meant to be comprehensive or referenced in detail, but only to emphasize some of lithium's unique properties, general tolerability, and multiple mechanisms of action. How lithium might fit into the new recommendations for pharmacoprophylaxis after a first manic episode is discussed.

\section{RESULTS}

\section{Some of the Assets of Lithium}

Lithium prevents depressions as well as manias. It is important to note that British naysayers and critics (Sheppard and Blackwood) said that lithium's use was based on a shaky foundation. Not only did Schou perform the critical studies to validate the efficacy of lithium in bipolar 
disorder, lithium continues to have the best record in longterm prophylaxis among a variety of agents (Baastrup and Schou, 1967). Its acute and prophylactic antimanic effects are amply demonstrated, and recent meta-analyses document its prophylactic antidepressant effects as well (Severus et al, 2014).

Acute and prophylactic effects in unipolar depression. A wealth of data indicate that compared with placebo, lithium acutely enhances the effects of antidepressants. Less well known is the strength of the data in the prophylaxis of recurrent unipolar depressive episodes and the prevention of suicide in this population as well (Abou-Saleh et al, 2017). These authors recommend lithium prophylaxis in unipolar depressed patients after 'the occurrence of 2 episodes of depression within 5 years... particularly in severe depression with psychotic features and high suicidal risk.... In some cases, lithium prophylaxis may be recommended after a single episode of depression that is severe with high suicidal risk and continued life-long.' In addition, in a new study in 123712 individuals hospitalized for a unipolar depression, prospective follow-up for a mean of 7.7 years revealed fewer rehospitalizations in those treated with lithium, whereas, surprisingly, those treated with either antidepressants or atypical antipsychotics did not show this reduced risk (Tiihonen et al, 2016).

Lithium has antisuicide effects, even in minute levels in the drinking water. Lithium has the best data to support its antisuicidal effects when used in therapeutic doses (AbouSaleh et al, 2017; Baldessarini et al, 2006; Toffol et al, 2015). However, miniscule but higher concentrations of lithium in the drinking water are associated with lower rates of suicide in the general population compared with locales with lesser amount of lithium. These findings have now been documented in more than a half dozen studies (Vita et al, 2015). One study reported a lower incidence of crimes, suicides, and arrests for drug use in adolescents (Schrauzer and Shrestha, 1990). Now a new study from Japan indicates higher levels in the water supply are associated with lower rates of depression and interpersonal violence in adolescents in the general population (Ando et al, 2017).

Lithium may reduce risk of dementia. Clinical use of lithium is associated with a lower incidence of dementia in old age (Kessing et al, 2010; Nunes et al, 2013). Moreover, excellent lithium responders have preserved cognition (Rybakowski and Suwalska, 2010). Lithium-treated patients have better visual memory than nonlithium patients (Bersani et al, 2016; Quartini et al, 2016).

In addition, minute doses of lithium (150 mg/day) exceed placebo in slowing the rate of cognitive deterioration over 1 year in elderly women with mild cognitive impairment (Forlenza et al, 2011). Positive effects of micro doses of lithium have been reported in Alzheimer's dementia (Nunes et al, 2013).

Lithium has neurotropic and neuroprotective effects. Lithium is associated with increases in hippocampal and cortical volume. This is likely based on its ability to increase neuroprotective factors $\mathrm{BDNF}$ and $\mathrm{BCl}-2$ and decrease apoptotic (cell death factors) BAX and P53 (Malhi et al, 2013; Rowe and Chuang, 2004). It increases neurogenesis and gliogenesis. In animal models, lithium lessens the size of lesions associated with AID neurotoxicity, ischemic/hemorrhagic stroke, traumatic brain/spinal cord injury (TBI/SCI), Huntington's disease (HD), Alzheimer's disease (AD), amyotrophic lateral sclerosis (ALS), fragile $\mathrm{X}$ syndrome (FXS), Parkinson's disease (PD), retinal degeneration, multiple sclerosis (MS), alcohol-induced degeneration, Down syndrome, spinocerebellar ataxia-1, and irradiation (Chiu et al, 2013).

Lithium increases telomere length. Lithium increases the length of telomeres whose preservation is necessary for maintaining both physical and psychiatric health. Lithium's effects on telomeres occurs as a direct result of increasing the activity of the telomere elongation enzyme-telomerase (Martinsson et al, 2013). The longer one is on lithium, the more normal the telomere length becomes (Squassina et al, 2016). Telomeres are shortened by childhood stressors, greater numbers of depressive episodes, and implacable anger, whereas they are lengthened by exercise, a good diet, mindfulness/meditation, and having positive and altruistic goals in life (Blackburn et al, 2015; Epel et al, 2004).

Lithium decreases incidence of some medical illnesses. Lithium may decrease the incidence of some neurological disorders such as seizures, amyotrophic lateral sclerosis (ALS), and dementia NOS, as well as myocardial infarction (Prosser and Fieve, 2016). Lithium, in a dose-related manner, also lowers the incidence of some cancers (Huang et al, 2016).

It also increases longevity in humans and several animal species (Zarse et al, 2011). It also reduces all-cause mortality in patients with bipolar disorder (Toffol et al, 2015). Whether any of these effects are secondary to its effects in lengthening telomeres remains to be demonstrated.

Lithium enhances the efficacy of multiple psychotropic drugs. In combination, lithium increases the efficacy of multiple agents in the acute and long-term treatment of bipolar disorder. These drugs include valproate, carbamazepine, lamotrigine, nimodipine, and most of the atypical antipsychotics with which it has been studied (Post, 2017; Post and Leverich, 2008).

\section{Lithium Side Effects: Often More Benign Than Presumed}

Contrary to conventional belief, lithium's side-effect profile at usual therapeutic doses is relatively benign. Moreover, if side effects such as tremor do occur at usual 'therapeutic' levels, doses can be reduced to below one's side-effect threshold, especially as many of lithium's clinical effects can be seen at lower levels (Post, 2016c,2017; Post and Leverich, 2008).

Although lithium can lower thyroid hormone levels, increase TRH, and induce hypothyroidism in $\sim 15 \%$ of individuals, this is easily corrected by thyroid hormone supplementation.

Lithium has been linked to deterioration in renal function evidenced by increasing creatinine levels and decreases in 
glomerular filtration rate (GFR) (Gupta and Khastgir, 2016). Tondo et al (2017) followed 512 bipolar patients and reported that lithium tended to begin to decrease estimated GFR (eGFR) after 10-15 years and risk of low values typically required 30 years of treatment, although no patient went on to end-stage renal failure requiring dialysis. They cited risk factors for decreased eGFR as longer lithium treatment, lower lithium dose, higher serum lithium concentration, older age (starting lithium at age $\geqslant 40$ years), medical comorbidity, and low initial baseline eGFR. However, recent reviews suggest that increased creatinine and low GFR may be related to episodes of toxicity (Clos et al, 2015), are seen just as often in patients maintained on anticonvulsants, and are not unique to lithium (Kessing et al, 2015). Moreover, the results of lithium discontinuation on those with elevated creatinine levels are ambiguous, although duration of lithium use and age appear to be risk factors for reduced GFR (Bocchetta et al, 2015). Use of minimum effective doses and careful monitoring is typically recommended (Gupta and Khastgir, 2016).

Although lithium can cause nephrogenic diabetes insipidus because of its block of antidiuretic effects (ie, inhibition of vasopressin effects at the level of adenylate cyclase), these can be moderated by amiloride and potentially by the carbonic anhydrase inhibitor acetazolamide (Bedford et al, 2008; de Groot et al, 2016). On a positive note, lithium can prevent or reverse the hyponatremia induced by carbamazepine (Brewerton and Jackson, 1994; Joffe et al, 1986; Vieweg et al, 1987). Lithium via its effects on colonystimulating factor (CSF) can reverse the benign white cell suppression of carbamazepine mediated by its inhibition of CSF(Kramlinger and Post, 1990).

Lithium can be associated with increases in serum calcium, sometimes related to the induction of secondary hyperparathyroidism by an adenoma. This can be worked up by measurement of parathyroid hormone, imaging of the parathyroid glands, and treated (if necessary) by surgery (Norlen et al, 2014). Lithium-induced tremor can be treated with dose reduction and $\beta$-blockers (Kellett et al, 1975).

Lithium can cause a variety of skin lesions, most often acne and psoriasis. These are often amenable to treatment, but in severe cases drug discontinuation may be required (Jafferany, 2008).

\section{Lithium Mechanisms and Predictors of Response}

How can a simple ion have such robust and diverse effects? Lithium is a medal ion $\mathrm{Li}+$ whose radius is close to that of sodium $\mathrm{Na}+$ and many of its actions resemble those of calcium $\mathrm{Ca}++$. Although it was initially thought that an understanding of lithium's mechanism of action would reveal the neuropathology underlying bipolar disorder, the panoply of its proposed actions has precluded this proposition. At the same time, the fact that lithium is such a 'dirty drug' with a multiplicity of actions (on neurotransmitters, receptors, second messengers, kinases, transcription factors, and genes) may be important to its diverse therapeutic effects, as the sheer numbers of its actions may lead to the reregulation of multiple pathways and abnormalities in bipolar disorder (Chiu et al, 2013; Malhi et al, 2013; Rowe and Chuang, 2004).
It is of interest that lithium appears to work best in those with: classical presentations of bipolar disorder; a positive family history of a mood or bipolar disorder; euphoric, rather than dysphoric, mania; and discrete episodes and clear well intervals. It works less well in those with rapid cycling or multiple episodes before starting treatment, and in those with an anxiety or substance comorbidity, or mood incongruent delusions (Post and Leverich, 2008). Those with a sequence of depression-mania-well interval (DMI) respond less well than those with a pattern of MDI (Koukopoulos et al, 2013). Several biochemical predictors of response have been reported, and confirmation of these is eagerly awaited.

\section{DISCUSSION: LITHIUM'S ROLE IN NEW CLINICAL RECOMMENDATIONS}

\section{Intensive Prophylactic Treatment after a First Manic Episode}

New data have changed the traditional recommendations for prophylaxis in bipolar disorder after several episodes to intensive, long-term prophylaxis after a first mania, although this is not yet uniformly into most treatment guidelines. The recommendation is based on the following principles.

There is increasing recognition that inadequately treated bipolar disorder can run a progressively deteriorating course (Kessing and Andersen, 2017; Post, 2016a, b, 2017). There is increased behavioral reactivity (sensitization) to the recurrences of stressors, mood episodes, and bouts of substance abuse, and there is cross-sensitization among each of these with the others (Post and Kalivas, 2013). Epigenetic alterations appear to underlie each type of sensitization, based on long-lasting chemical alterations in DNA, histones, or microRNA (Post, 2017). Kessing and Andersen (2017) systematically review the literature on illness progression and find considerable evidence for an association between the number of episodes in unipolar and bipolar disorder and: risk of recurrence; decreased probably of recovery; increased severity; a lowering of the threshold for stressors to precipitate episodes; and a progression of cognitive deficits.

Thus, it is imperative to initiate treatment in the most expeditious manner possible to prevent the dysfunction, disability, morbidity, and mortality that all too often accompanies bipolar disorder, and often occurs as a function of the number of prior episodes (Kessing and Andersen, 2017; Post et al, 2012). Proper treatment from the outset appears critical to minimizing the impact of bipolar illness on one's psychological and medical health. Recommendations for long-term prophylaxis starting with the first manic episode are based on the empirical data of three recent studies noted below, as well as the theoretical rationales noted above.

(1) Kessing et al (2013) reported that comprehensive specialty clinic treatment resulted in many fewer relapses than treatment as usual (TAU). Such specialty treatment involved hospital transition counseling, illness education, psychotherapy, pharmacotherapy, mood monitoring, and early symptom recognition. When this was initiated on a randomized basis for 2 years compared with TAU, the outcome in those with specialty treatment was superior to TAU not only for these 2 years, but also for the next 4 years 
even though all patients returned to TAU after 2 years, suggesting that the clinic patients had learned to manage their illness better (Kessing et al, 2013). 'One must conclude that initial intensive and comprehensive treatment can change the course of bipolar disorder and make it a more benign illness.'

(2) Yatham et al (2017) reported that cognitive deficits seen after a first mania improve over the next year only if there are no further new mood episodes. Cognitive deficits increase as a function of the number of mood episodes, either depressions or manias (Kessing and Andersen, 2017; Post et al, 2012). Deficits start after a first mania and are not remediated if further episodes occur within the first year (Yatham et al, 2017). The message is clear: one must prevent further episodes even after a first mania to protect cognition and its association with dysfunction and other aspects of illness progression.

(3) Berk et al (2017) reported on the comparative efficacy of a year of randomized treatment with either lithium or the atypical antipsychotic quetiapine after a first episode. Compared with quetiapine, the outcome in those randomized to lithium was superior on all measures, and the differences became apparent and increasingly so in the past 6 months of the first year. This included: all aspects of mania and depression; functioning; cognition; and brain imaging measures of white matter volume. Thus, it would appear prudent for lithium to be included in the long-term treatment regimen if at all possible, based not only on the data of Berk et al (2017), but the multiple other assets of lithium summarized above.

\section{Earlier Recognition of Children in the United States at High Risk for Early-Onset Bipolar Disorder}

Recent data indicate that in the United States, youngsters are at a higher risk of a childhood-onset ( $<13$ years of age) bipolar disorder and its related conditions and comorbidities than those from Canada, the Netherlands, Germany, and multiple other European countries (Post et al, 2017). This appears based to a large extent on a greater burden of multiple generation genetic vulnerability and increases in adversity in childhood, possibly along with a host of other variables including poor diet, obesity, and the like. Earlyonset illness is associated with a longer duration of delay to first treatment, and both early onset and treatment delay are risk factors for a poor outcome in adulthood (Post et al, 2017, 2010). Much of the current treatment of childhoodonset bipolar disorder leaves much to be desired. For example, Geller et al (2010) reported that $37 \%$ of the children (average age 11 years) with a bona fide research diagnosis of bipolar disorder never received any of the consensus recommended treatments over an 8-year followup in the community. Those who did receive lithium did the best and had the highest rates of remission.

We are not necessarily suggesting greater use of lithium in children with bipolar disorder the United States, even though recent studies confirm its efficacy in mania (Findling et al, 2015), as the necessary comparative studies have not been performed to inform optimal treatment. For example, Geller et al (2012) found superiority of an atypical antipsychotic over either lithium or valproate in childhood bipolar disorder. Nonetheless, better recognition of the substantial incidence of childhood-onset bipolar disorder in the United States and earlier initiation of appropriate psychosocial (Miklowitz et al, 2013) and pharmacological treatment may be life saving.

\section{CONCLUSIONS}

Lithium is underutilized in the treatment of bipolar disorder, especially in the United States compared with the Netherlands and Germany (Post et al, 2011), and likely many other European countries. Disappointingly, Baldessarini et al (2007) revealed in 7760 adults with a new-onset bipolar disorder diagnosis in a general practice in the United States that patients were rarely treated with lithium $(7.5 \%)$, any mood stabilizer $(24.6 \%)$, or an antipsychotic (10.7\%), but were given antidepressants, which are not recommended, $49.8 \%$ of the time. In an epidemiological survey, $80 \%$ of adolescents meeting criteria for a bipolar spectrum disorder were not in treatment of any kind (Merikangas et al, 2010).

We do not know for sure whether greater use of lithium in adults with bipolar disorder in the United States would help render the illness more benign, but it is clear that early expert treatment is a good place to start (Kessing et al, 2013, 2014). In concert with new treatment research and public health efforts, it is hoped that early recognition and treatment may begin to ameliorate some of the devastation of multigenerational transmission of bipolar disorder in the United States and around the world. It would appear that greater consideration of the use of lithium for prevention of unipolar and bipolar disorder and their associated high risks of suicide and increased medical mortality is indicated. This is a message that Mogens Schou promulgated throughout his extraordinary clinical and scientific career, and now even more data exist to support this conclusion.

\section{FUNDING AND DISCLOSURE}

RMP declares no conflict of interest that is directly pertinent to the topic of this article, although he has been a speaker for Astra Zeneca, Sunovion, Validus, and Takeda in the past year.

Comments on lithium from Robert M. Post, the winner of the 2017 ISBD Mogens Schou Award for Research, 4 May 2017

\section{REFERENCES}

Abou-Saleh MT, Muller-Oerlinghausen B, Coppen AJ (2017). Lithium in the episode and suicide prophylaxis and in augmenting strategies in patients with unipolar depression. Int J Bipolar Disord 5: 11.

Ando S, Koike S, Shimodera S, Fujito R, Sawada K, Terao T et al (2017). Lithium levels in tap water and the mental health problems of adolescents: an individual-level crosssectional survey. J Clin Psychiatry 78: e252-e256.

Baastrup PC, Schou M (1967). Lithium as a prophylactic agents. Its effect against recurrent depressions and manic-depressive psychosis. Arch Gen Psychiatry 16: 162-172.

Baldessarini RJ, Leahy L, Arcona S, Gause D, Zhang W, Hennen J (2007). Patterns of psychotropic drug prescription for U.S. patients with diagnoses of bipolar disorders. Psychiatr Serv 58: 85-91. 
Baldessarini RJ, Tondo L, Davis P, Pompili M, Goodwin FK, Hennen J (2006). Decreased risk of suicides and attempts during long-term lithium treatment: a meta-analytic review. Bipolar Disord 8(5 Pt 2): 625-639.

Bedford JJ, Weggery S, Ellis G, McDonald FJ, Joyce PR, Leader JP et al (2008). Lithium-induced nephrogenic diabetes insipidus: renal effects of amiloride. Clin J Am Soc Nephrol 3: 1324-1331.

Berk M, Daglas R, Dandash O, Yucel M, Henry L, Hallam K et al (2017). Quetiapine v. lithium in the maintenance phase following a first episode of mania: randomised controlled trial. $\mathrm{Br} J$ Psychiatry 210: 413-442.

Bersani G, Quartini A, Zullo D, Iannitelli A (2016). Potential neuroprotective effect of lithium in bipolar patients evaluated by neuropsychological assessment: preliminary results. Hum Psychopharmacol 31: 19-28.

Blackburn EH, Epel ES, Lin J (2015). Human telomere biology: a contributory and interactive factor in aging, disease risks, and protection. Science 350: 1193-1198.

Bocchetta A, Ardau R, Fanni T, Sardu C, Piras D, Pani A et al (2015). Renal function during long-term lithium treatment: a cross-sectional and longitudinal study. BMC Med 13: 12.

Brewerton TD, Jackson CW (1994). Prophylaxis of carbamazepineinduced hyponatremia by demeclocycline in six patients. J Clin Psychiatry 55: 249-251.

Chiu CT, Wang Z, Hunsberger JG, Chuang DM (2013). Therapeutic potential of mood stabilizers lithium and valproic acid: beyond bipolar disorder. Pharmacol Rev 65: 105-142.

Clos S, Rauchhaus P, Severn A, Cochrane L, Donnan PT (2015). Long-term effect of lithium maintenance therapy on estimated glomerular filtration rate in patients with affective disorders: a population-based cohort study. Lancet Psychiatry 2: 1075-1083.

de Groot T, Sinke AP, Kortenoeven ML, Alsady M, Baumgarten R, Devuyst $O$ et al (2016). Acetazolamide attenuates lithium-induced nephrogenic diabetes insipidus. J Am Soc Nephrol 27: 2082-2091.

Epel ES, Blackburn EH, Lin J, Dhabhar FS, Adler NE, Morrow JD et al (2004). Accelerated telomere shortening in response to life stress. Proc Natl Acad Sci USA 101: 17312-17315.

Findling RL, Robb A, McNamara NK, Pavuluri MN, Kafantaris V, Scheffer R et al (2015). Lithium in the acute treatment of bipolar i disorder: a double-blind, placebo-controlled study. Pediatrics 136: 885-894.

Forlenza OV, Diniz BS, Radanovic M, Santos FS, Talib LL, Gattaz WF (2011). Disease-modifying properties of long-term lithium treatment for amnestic mild cognitive impairment: randomised controlled trial. Br J Psychiatry 198: 351-356.

Geller B, Luby JL, Joshi P, Wagner KD, Emslie G, Walkup JT et al (2012). A randomized controlled trial of risperidone, lithium, or divalproex sodium for initial treatment of bipolar I disorder, manic or mixed phase, in children and adolescents. Arch Gen Psychiatry 69: 515-528.

Geller B, Tillman R, Bolhofner K, Zimerman B (2010). Pharmacological and non-drug treatment of child bipolar I disorder during prospective eight-year follow-up. Bipolar Disord 12: 164-171.

Grof P (2006). Obituary for Mogens Schou (1918-2005). Neuropsychopharmacology 31: 891-892.

Gupta S, Khastgir U (2016). Drug information update. Lithium and chronic kidney disease: debates and dilemmas. BJPsych Bull 41: 216-220.

Huang RY, Hsieh KP, Huang WW, Yang YH (2016). Use of lithium and cancer risk in patients with bipolar disorder: populationbased cohort study. Br J Psychiatry 209: 393-399.

Jafferany M (2008). Lithium and psoriasis: what primary care and family physicians should know. Prim Care Companion J Clin Psychiatry 10: 435-439.

Joffe RT, Post RM, Uhde TW (1986). Effects of carbamazepine on serum electrolytes in affectively ill patients. Psychol Med 16: 331-335.
Kellett JM, Metcalfe M, Bailey J, Coppen AJ (1975). Beta blockade in lithium tremor. J Neurol Neurosurg Psychiatry 38: 719-721.

Kessing LV, Andersen PK (2017). Evidence for clinical progression of unipolar and bipolar disorders. Acta Psychiatr Scand 135: 51-64.

Kessing LV, Forman JL, Andersen PK (2010). Does lithium protect against dementia? Bipolar Disord 12: 87-94.

Kessing LV, Gerds TA, Feldt-Rasmussen B, Andersen PK, Licht RW (2015). Use of lithium and anticonvulsants and the rate of chronic kidney disease: a nationwide population-based study. JAMA Psychiatry 72: 1182-1191.

Kessing LV, Hansen HV, Hvenegaard A, Christensen EM, Dam H, Gluud C et al (2013). Treatment in a specialised out-patient mood disorder clinic v. standard out-patient treatment in the early course of bipolar disorder: randomised clinical trial. $\mathrm{Br} J$ Psychiatry 202: 212-219.

Kessing LV, Vradi E, Andersen PK (2014). Starting lithium prophylaxis early v. late in bipolar disorder. Br J Psychiatry 205: 214-220.

Koukopoulos A, Reginaldi D, Tondo L, Visioli C, Baldessarini RJ (2013). Course sequences in bipolar disorder: depressions preceding or following manias or hypomanias. J Affect Disord 151: 105-110.

Kramlinger KG, Post RM (1990). Addition of lithium carbonate to carbamazepine: hematological and thyroid effects. Am J Psychiatry 147: 615-620.

Malhi GS, Tanious M, Das P, Coulston CM, Berk M (2013). Potential mechanisms of action of lithium in bipolar disorder. Current understanding. CNS Drugs 27: 135-153.

Martinsson L, Wei Y, Xu D, Melas PA, Mathe AA, Schalling M et al (2013). Long-term lithium treatment in bipolar disorder is associated with longer leukocyte telomeres. Transl Psychiatry 3: e261.

Merikangas KR, He JP, Burstein M, Swanson SA, Avenevoli S, Cui L et al (2010). Lifetime prevalence of mental disorders in U.S. adolescents: results from the National Comorbidity Survey Replication-Adolescent Supplement (NCS-A). J Am Acad Child Adolesc Psychiatry 49: 980-989.

Miklowitz DJ, Schneck CD, Singh MK, Taylor DO, George EL, Cosgrove VE et al (2013). Early intervention for symptomatic youth at risk for bipolar disorder: a randomized trial of family-focused therapy. J Am Acad Child Adolesc Psychiatry 52: 121-131.

Norlen O, Sidhu S, Sywak M, Delbridge L (2014). Long-term outcome after parathyroidectomy for lithium-induced hyperparathyroidism. Br J Surg 101: 1252-1256.

Nunes MA, Viel TA, Buck HS (2013). Microdose lithium treatment stabilized cognitive impairment in patients with Alzheimer's disease. Curr Alzheimer Res 10: 104-107.

Post RM (2016a). Epigenetic basis of sensitization to stress, affective episodes, and stimulants: implications for illness progression and prevention. Bipolar Disord 18: 315-324.

Post RM (2016b)Preventing sensitization and kindling-like progression in the recurrent affective disordersIn:Chiccetti $\mathrm{D}(\mathrm{ed})$ Developmental Psychopathy. John Wiley \& Sons: Hoboken, NJVol 3 pp 971-996.

Post RM (2016c). Treatment of bipolar depression: evolving recommendations. Psychiatr Clin North Am 39: 11-33.

Post RM (2017). New perspectives on the course and treatment of bipolar disorder. Minerva Med 58: 40-53.

Post RM, Altshuler LL, Kupka R, McElroy SL, Frye MA, Rowe M et al (2017). More childhood onset bipolar disorder in the United States than Canada or Europe: implications for treatment and prevention. Neurosci Biobehav Rev 74(Pt A): 204-213.

Post RM, Fleming J, Kapczinski F (2012). Neurobiological correlates of illness progression in the recurrent affective disorders. $J$ Psychiatr Res 46: 561-573. 
Post RM, Kalivas P (2013). Bipolar disorder and substance misuse: pathological and therapeutic implications of their comorbidity and cross-sensitisation. $\mathrm{Br} J$ Psychiatry 202: 172-176.

Post RM, Leverich GS (2008). Treatment of Bipolar Illness: A Casebook for Clinicians and Patients. WW Norton \& Company: New York, NY.

Post RM, Leverich GS, Altshuler LL, Frye MA, Suppes T, Keck PE et al (2011). Differential clinical characteristics, medication usage, and treatment response of bipolar disorder in the US versus The Netherlands and Germany. Int Clin Psychopharmacol 26: 96-106.

Post RM, Leverich GS, Kupka RW, Keck PE Jr, McElroy SL, Altshuler LL et al (2010). Early-onset bipolar disorder and treatment delay are risk factors for poor outcome in adulthood. $J$ Clin Psychiatry 71: 864-872.

Prosser JM, Fieve RR (2016). Patients receiving lithium therapy have a reduced prevalence of neurological and cardiovascular disorders. Prog Neuropsychopharmacol Biol Psychiatry 71: 39-44.

Quartini A, Iannitelli A, Bersani G (2016). Lithium: from mood stabilizer to putative cognitive enhancer. Neural Regen Res 11: 1234-1235.

Rowe MK, Chuang DM (2004). Lithium neuroprotection: molecular mechanisms and clinical implications. Expert Rev Mol Med 6: $1-18$.

Rybakowski JK, Suwalska A (2010). Excellent lithium responders have normal cognitive functions and plasma BDNF levels. Int $J$ Neuropsychopharmacol 13: 617-622.

Schrauzer GN, Shrestha KP (1990). Lithium in drinking water and the incidences of crimes, suicides, and arrests related to drug addictions. Biol Trace Elem Res 25: 105-113.

Severus E, Taylor MJ, Sauer C, Pfennig A, Ritter P, Bauer M et al (2014). Lithium for prevention of mood episodes in bipolar disorders: systematic review and meta-analysis. Int $J$ Bipolar Disord 2: 15.

Squassina A, Pisanu C, Congiu D, Caria P, Frau D, Niola P et al (2016). Leukocyte telomere length positively correlates with duration of lithium treatment in bipolar disorder patients. Eur Neuropsychopharmacol 26: 1241-1247.

Tiihonen J, Lahteenvuo M, Hoti F, Vattulainen P, Taipale H, Tanskanen A(eds) (2016). Real-World Effectiveness of
Pharmacological Treatments in Severe Unipolar Depression in a Nationwide Cohort of 123,712 Patients. American College of Neuropsychopharmacology: Hollywood, FL.

Toffol E, Hatonen T, Tanskanen A, Lonnqvist J, Wahlbeck K, Joffe $\mathrm{G}$ et al (2015). Lithium is associated with decrease in all-cause and suicide mortality in high-risk bipolar patients: a nationwide registry-based prospective cohort study. J Affect Disord 183: 159-165.

Tondo L, Abramowicz M, Alda M, Bauer M, Bocchetta A, Bolzani L et al (2017). Long-term lithium treatment in bipolar disorder: effects on glomerular filtration rate and other metabolic parameters. Int J Bipolar Disord 5: 27.

Vieweg V, Glick JL, Herring S, Kerler R, Godleski LS, Barber J et al (1987). Absence of carbamazepine-induced hyponatremia among patients also given lithium. Am J Psychiatry 144: 943-947.

Vita A, De Peri L, Sacchetti E (2015). Lithium in drinking water and suicide prevention: a review of the evidence. Int Clin Psychopharmacol 30: 1-5.

Yatham LN, Mackala S, Basivireddy J, Ahn S, Walji N, Hu C et al (2017). Lurasidone versus treatment as usual for cognitive impairment in euthymic patients with bipolar I disorder: a randomised, open-label, pilot study. Lancet Psychiatry 4: 208-217.

Zarse K, Terao T, Tian J, Iwata N, Ishii N, Ristow M (2011). Lowdose lithium uptake promotes longevity in humans and metazoans. Eur J Nutr 50: 387-389.

This work is licensed under a Creative Commons Attribution-NonCommercial-ShareAlike $\quad 4.0$ International License. The images or other third party material in this article are included in the article's Creative Commons license, unless indicated otherwise in the credit line; if the material is not included under the Creative Commons license, users will need to obtain permission from the license holder to reproduce the material. To view a copy of this license, visit http://creativecommons.org/licenses/by-nc-sa/4.0/

(C) The Author(s) 2018 